\title{
Ophiocordyceps sinensis: A prominent source of bioactive components for alleviating overactive bladder
}

\author{
Pang Li Yin', Tan Chon Seng'2, Ng Szu Ting', Lim Kuan Hon', Then Sue \\ Mian $^{1}$ and Ting Kang Nee ${ }^{1, *}$ \\ ${ }^{1}$ School of Pharmacy, University of Nottingham Malaysia, Jalan Broga, 43500 Semenyih, Malaysia. \\ ${ }^{2}$ LiGNO Biotech Sdn Bhd, 43300, Balakong Jaya, Malaysia.
}

\section{ABSTRACT}

Ophiocordyceps sinensis is one of the most sought-after medicinal fungi used to treat various medical conditions such as respiratory diseases, liver and kidney dysfunctions. In China, it is widely used for alleviation of urinary symptoms where patients treated with $O$. sinensis have shown improvement in frequent urination and nocturia, the two most common symptoms of overactive bladder $(\mathrm{OAB})$. Many studies have reported its anti-inflammatory, anti-oxidative, cytotoxic, hypoglycaemic and vasorelaxation properties. These properties are attributable to the presence of bioactive components such as polysaccharides, proteins and nucleosides. This mini-review highlights the medicinal potential of $O$. sinensis in alleviating $\mathrm{OAB}$, which is a debilitating condition with a profound impact on the quality of life in a high proportion of older people. Four possible mechanisms of action of $O$. sinensis are suggested. Firstly, the relaxation of detrusor muscle through calcium dynamic, production of nitric oxide (NO) and adenosine triphosphate (ATP). A second mechanism proposed is through the suppression of micturition reflex, targeting the neurogenic $\mathrm{OAB}$. The unequivocal anti-inflammation and anti-oxidative properties of $O$. sinensis are two other plausible explanations, as both chronic inflammation and accumulation of oxidative stress molecules are associated with $\mathrm{OAB}$ exacerbation. With the recent success in cultivation of $O$. sinensis and the positive results from toxicity studies, a better understanding of its pharmacological actions can be further substantiated, including its use for relieving $\mathrm{OAB}$.

Keywords: Ophiocordyceps sinensis; medicinal fungi; overactive bladder; nocturia

* Correspondence

Ting Kang Nee

School of Pharmacy

University of Nottingham Malaysia Jalan Broga, 43500 Semenyih

Malaysia

Kang-Nee.Ting@nottingham.edu.my Tel: +60389248209

Received: 7 August 2020

Revised: 20 October 2020

Accepted: 6 November 2020

Published: 11 November 2020

doi

https://doi.org/10.28916/lsmb.4.9.2020.67

\section{INTRODUCTION}

Overactive bladder $(\mathrm{OAB})$ is a devastating condition that significantly affects the quality of life of patients in the social, occupational, domestic, physical, sexual and psychological aspects (Abrams, Kelleher, Kerr, \& Rogers, 2000). According to the World Health Organisation (WHO), the prevalence of $\mathrm{OAB}$ reported in population-based studies ranges from $9.9 \%$ to $36.1 \%$, and it is highly prevalent in older people aged 60 years and over (World Health Organization, 2017). OAB appears to have a multifactorial etiology that includes myogenic, neurogenic and urotheliogenic in origin (Brading, 1997; De Groat, 1997; Tyagi, 2011). Recent studies also revealed the association of metabolic syndrome with $\mathrm{OAB}$ as a result of inflammation and oxidative stress that arise from conditions such as atherosclerosis, diabetes and obesity (He et al., 2016). There is a deficit in knowledge on the mechanism of $\mathrm{OAB}$ as idiopathic $\mathrm{OAB}$ is seen in many patients and represents one of the main hurdles in managing this condition (Hanna-Mitchell, Kashyap, Chan, Andersson, \& Tannenbaum, 2014). A summary of the pathophysiology of OAB is illustrated in Table 1. Generally, $\mathrm{OAB}$ involves an uninhibited elevation of intravesical pressure during the storage phase, leading to enhanced spontaneous myogenic activity and fused tetanic contractions of the bladder (Steers, 2002). 
Table 1: Pathophysiology of overactive bladder

\begin{tabular}{|c|c|c|}
\hline Etiology of Overactive Bladder & Mechanism & Reference \\
\hline \multirow[t]{2}{*}{ Myogenic } & $\begin{array}{l}\text { Alterations in the properties and structure of detrusor cause spontaneous rises of intravesical } \\
\text { pressure hence increase excitability and electrical coupling between cells. Innervation then } \\
\text { spread throughout the bladder wall and result in myogenic contraction of the entire bladder. }\end{array}$ & (Brading, 1997) \\
\hline & $\begin{array}{l}\text { Abnormal } \mathrm{Ca}^{2+} \text { activities mediated by extracellular calcium influx and intracellular calcium } \\
\text { release lead to spontaneous detrusor muscle contraction. }\end{array}$ & $\begin{array}{l}\text { (Sui, Fry, } \\
\text { Malone-Lee, \& } \\
\text { Wu, 2009) }\end{array}$ \\
\hline \multirow[t]{3}{*}{ Neurogenic } & $\begin{array}{l}\text { Damage to the brain suppresses suprapontine inhibition and damage to axonal pathways in the } \\
\text { spinal cord may trigger the C-fiber bladder afferent nerves, resulting in involuntary muscle } \\
\text { contractions during the filling stage. }\end{array}$ & (De Groat, 1997) \\
\hline & $\begin{array}{l}\text { Upregulation of transient receptor potential vanilloid type } 1 \text { (TRPV1) receptors on the C-fiber } \\
\text { nerve endings, following damage to the brain or spinal cord may result in involuntary } \\
\text { micturition. }\end{array}$ & $\begin{array}{l}\text { (de Groat \& } \\
\text { Yoshimura, 2012 } \\
\text { Park, Jung, Cho, } \\
\text { Jin, \& Hong, } \\
\text { 2018) }\end{array}$ \\
\hline & $\begin{array}{l}\text { Upregulation of nicotinic acetylcholine receptors in pelvic ganglion neurons may potentiate } \\
\text { ganglionic transmission and cause detrusor overactivity. }\end{array}$ & $\begin{array}{l}\text { (Chung, Lee, } \\
\text { Park, \& Jeong, } \\
\text { 2015) }\end{array}$ \\
\hline \multirow[t]{2}{*}{ Urotheliogenic } & $\begin{array}{l}\text { Damage to the urothelium lining diminishes the barrier function of the urothelium causing } \\
\text { water, urea and toxic substances to pass into underlying tissue hence causing symptoms of } \\
\text { urinary urgency, frequency and pain. }\end{array}$ & $\begin{array}{l}\text { (Apodaca et al., } \\
2003 \text { ) }\end{array}$ \\
\hline & $\begin{array}{l}\text { Alterations in the level of urothelial signalling molecules such as nitric oxide (NO) and adenosine } \\
\text { triphosphate (ATP). }\end{array}$ & $\begin{array}{l}\text { (Winder, Tobin, } \\
\text { Zupančič, \& } \\
\text { Romih, 2014) }\end{array}$ \\
\hline \multirow{3}{*}{$\begin{array}{l}\text { Secondary to metabolic } \\
\text { syndrome such as atherosclerosis, } \\
\text { obesity, insulin resistance }\end{array}$} & $\begin{array}{l}\text { Upregulation of } \mathrm{M}_{3} \text { receptors and L-type calcium channels in diabetic bladder enhances } \\
\text { muscarinic activation and influx of extracellular calcium. }\end{array}$ & $\begin{array}{l}\text { (Leiria et al., } \\
\text { 2011) }\end{array}$ \\
\hline & $\begin{array}{l}\text { Elevation of pro-inflammatory cytokines IL-1, IL- } 6 \text {, histamine and TNF- } \alpha \text { in metabolic } \\
\text { syndrome may directly sensitise afferent nerve terminals and result in OAB. Inhibition of these } \\
\text { pro-inflammatory cytokines has shown to improve OAB symptoms. }\end{array}$ & $\begin{array}{l}\text { (Tyagi et al., } \\
\text { 2010; Z. Wang et } \\
\text { al., 2012) }\end{array}$ \\
\hline & $\begin{array}{l}\text { Oxidative stress during disease state may lead to bladder ischaemia and reperfusion which in } \\
\text { turn, damage and impair contractility of the detrusor. }\end{array}$ & $\begin{array}{l}\text { (Nomiya, } \\
\text { Andersson, \& } \\
\text { Yamaguchi, } \\
\text { 2015) }\end{array}$ \\
\hline
\end{tabular}

Therefore, regardless of the origin, patients with $\mathrm{OAB}$ experience similar symptoms, including urinary urgency, incontinence and most commonly, urinary frequency and nocturia. A national survey conducted in the USA showed that at least $66.8 \%$ of the OAB patients suffered from nocturia (Coyne et al., 2003). Although OAB is not a lifethreatening condition, it is concerned that people with nocturia may have a higher mortality rate than the general population (Endeshaw et al., 2016).

Currently, the management of $\mathrm{OAB}$ consists of conservative therapy and pharmacological intervention (Srikrishna, Robinson, Cardozo, \& Vella, 2007). Conservative therapy is also known as behavioural therapy, involves lifestyle modification such as limiting consumption of water, avoiding alcohol or caffeine intake, bladder retraining and/or performing pelvic floor exercise. Pharmacotherapeutic agents including antimuscarinics and $\beta_{3^{-}}$ adrenoceptor agonist (mirabegron) are usually commenced if patients are unable to perform conservative therapy or if symptoms do not improve after six months (National Institute For Health and Care \& Excellence, 2015). However, these medications are associated with various unpleasant effects that often lead to non-compliance and treatment failure. Dry mouth and constipation are the most common side effects experienced by antimuscarinic users due to the abundance of muscarinic $M_{2}$ and $M_{3}$ receptors at the salivary glands and gastrointestinal tract (Athanasopoulos \& Giannitsas, 2011). Other side effects include blurred vision, dizziness and cognitive impairment. These effects are enhanced in those who are taking concurrent medications such as antiemetics, bronchodilators and antipsychotics as they are also blocking these muscarinic receptors. Whilst not contributing to the muscarinic burden, mirabegron may cause dizziness, back pain and cardiovascular-related adverse effects such as hypertension and tachycardia (O. Yamaguchi et al., 2015). In refractory $\mathrm{OAB}$, minimally invasive treatment including botulinum toxin $\mathrm{A}$ (Botox A) injection and sacral neuromodulation are available (Srikrishna et al., 2007). These methods are expensive and require expert management and they are not suitable for routine use. Furthermore, they can only provide temporary relief for up to six months.

Undoubtedly, there is a demand for alternative treatment to alleviate $\mathrm{OAB}$. In this regard, herbal and natural products that represent promising sources of bioactive components are increasingly popular among patients with OAB (Chughtai et al., 2013). In China, Ophiocordyceps sinensis (Berk.) G.H. Sung, J.M. Sung, Hywel-Jones \& Spatafora, one of the most sought-after medicinal fungi, has been used traditionally for frequent urination (Winston \& Maimes, 2007). Several studies have also reported that patients treated with $O$. sinensis have shown improvement in urinary symptoms, particularly nocturia, which is the most common symptom of OAB (Bao, Wu, \& Zheng, 1994; Z. J. Zhang, Luo, \& Li, 1997). This mini-review aims to summarise the known bioactive components of $O$. sinensis, along with its possible mechanisms of action for alleviating $\mathrm{OAB}$. These include detrusor muscle relaxation, inhibition of micturition reflex, anti-inflammation and anti-oxidation.

\section{OPHIOCORDYCEPS SINENSIS AND ITS KNOWN BIOACTIVE CONSTITUENTS}

O. sinensis is an entomopathogenic fungus in the family Ophiocordycipitaceae which mainly distributed on the Tibetan Plateau and its surrounding regions, namely Tibet, Gansu, Qinghai, Sichuan, Yunnan and areas above $3000 \mathrm{~m}$ in Bhutan, Nepal and India (Yi Li et al., 2011). It is commonly known as "Dong Chong Xia Cao" in Chinese and "yartsa gunbu" in Tibetan, which both mean winter worm-summer grass due to its interesting life-cycle. It parasitises the larva of ghost moth in summer, then forms a sporulating structure from the larva after overwintering (Figure 1) (Lo, Hsieh, Lin, \& Hsu, 2013). According to the first official record of O. sinensis in the Compendium of Materia Medica 1694 by Wang Ang, O. sinensis is beneficial for many conditions including respiratory diseases, liver and kidney dysfunction, as well as a general tonic to strengthen the overall health (Winkler, 2011). In recent years, it has been a focus for biochemical and pharmacological studies 


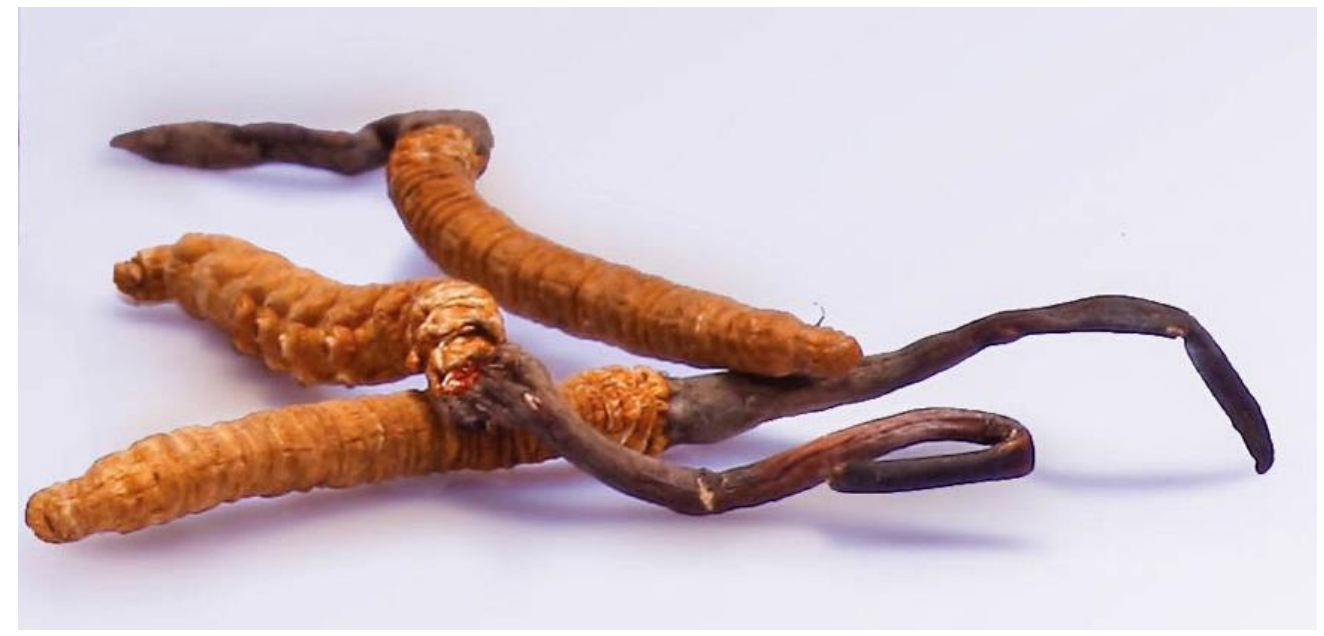

Figure 1: Wild Ophiocordyceps sinensis. After being infected by the spores of O. sinensis, contents of the larva will be gradually replaced by sclerotium and become a nutrient store for the fungus. Following overwintering, the fungal fruiting body (dark brown) sporulates from the sclerotium i.e. the caterpillar body (light brown) and emerges above the soil surface.

aiming to validate and provide scientific evidence to support the claims of its efficacious traditional medicinal uses.

As a prominent source of bioactive components, $O$. sinensis has shown to elicit several pharmacological actions including antiinflammation, anti-oxidation, cytotoxic, hypoglycaemic, and vasorelaxation (Chiou, Chang, Chou, \& Chen, 2000; Ji et al., 2011; S. P. Li, Li, Dong, \& Tsim, 2001; S. P. Li et al., 2006; M. L. Yang, Kuo, Hwang, $\& \mathrm{Wu}, 2011)$. Polysaccharides are one of the major components of $O$. sinensis and they are purported to be the main contributors to the overall pharmacological effects (Y. Liu et al., 2015). These include cordyglucans, $\beta-1,3 / 1,6$-glucans, the acidic polysaccharide AEPS-1, which composed of glucopyranose and pyrano-glucuronic acid, and the water-soluble polysaccharide CME-1, which composed of mannose and galactose (Lu et al., 2014; Z. M. Wang et al., 2011; Yalin, Ishurd, Cuirong, \& Yuanjiang, 2005). Proteins, amino acids and polypeptides also contribute to the bioactivity of $O$. sinensis. A few studies have explored the effect of cordymin and cordycedipeptide A, which are peptides purified from $O$. sinensis (Jia, Ma, Wu, Wu, \& Hu, 2005; Qi et al., 2013; Qian, Pan, \& Guo, 2012). In addition, 18 amino acids were detected in O. sinensis with glutamic acid and aspartic acid being the most abundant (Hsu, Shiao, Hsieh, \& Chang, 2002; Y. Liu et al., 2015).

Nucleobases, nucleotides and nucleosides which have important roles in maintaining normal physiology are also detected in both natural and cultured $O$. sinensis using ion-pairing reversed-phase liquid chromatography-mass spectrometry (F. Q. Yang, Li, Feng, Hu, \& Li, 2010). These include six nucleobases which are adenine, guanine, uracil, hypoxanthine, cytosine and thymine; three nucleotides that include uridine-5'-monophosphate (UMP), adenosine-5'-monophosphate (AMP) and guanosine-5'-monophosphate (GMP); and seven nucleosides, namely, adenosine, guanosine, uridine, inosine, thymidine, cytidine and cordycepin. Some studies suggested that the amount of cordycepin in artificially cultured O. sinensis is much lower than those in the wild (Khan, Parveen, Mishra, Tulsawani, \& Ahmad, 2015; F. Q. Yang et al., 2010). However, a large amount of cordycepin (0.66 g per $\mathrm{kg}$ ) has been detected in the fruiting bodies of $O$. sinensis cultivated in rice-based media (Fung, Cheong, Tan, Ng, \& Tan, 2018). This contrasting outcome suggests that the different cultivation methods can affect the chemical composition of the cultivated fungi. CSDNase, an acid deoxyribonuclease, is another compound purified from the cultured mycelia of $O$. sinensis and has identical nucleolytic properties with other well-characterised acid DNases (Ye et al., 2004). Sterols that are commonly found in fungi have also been detected in $O$. sinensis. These include ergosterol and H1-A, an ergosterol-like sterol (Peng et al., 2014; L. Y. Yang, Chen, Kuo, \& Lin, 1999). Other compounds include cordycepic acid, phenols, flavonoids, vitamins and microelements (Chatterjee, Srinivasan, \& Maiti, 1957; Mamta et al., 2015).
PROPOSED MECHANISMS OF ACTION OF O. SINENSIS IN ALLEVIATING OAB

\section{Promoting detrusor muscle relaxation}

\section{Inhibition of extracellular calcium influx}

The aberration of calcium influx and intracellular calcium release as well as upregulation of L-type calcium channels are part of the contributing factors of $\mathrm{OAB}$ (see Table 1). Therefore, modulation of calcium activity is recognised as one of the therapeutic targets for $\mathrm{OAB}$. In a previous study, intravesical instillation of verapamil, a calciumchannel blocker, has shown to significantly increase the bladder capacity in patients with detrusor hyperreflexia (Mattiasson, Ekstrom, \& Andersson, 1989). Besides, administration of amlodipine, a dihydropyridine calcium-channel blocker, decreased the bladder index and prolonged the micturition interval of rats with benign prostatic hyperplasia (H. P. Liu, Chen, Liu, \& Xu, 2009). Several medicinal fungi and their polysaccharides extracts have demonstrated calcium channel inhibition property. $\beta$-glucans from Schizophyllum commune have shown to induce a marked relaxation in vascular smooth muscles by blocking calcium-activated chloride channels (Chen et al., 2014). Recently, high molecular weight fractions of Lignosus rhinocerus which contain a large amount of glucans have also exhibited airway relaxant effect in rats via blockade of calcium channels (Lee et al., 2018). Due to the abundance of polysaccharides in $O$. sinensis and the similarities in smooth muscle contraction mechanism, it is probable that $O$. sinensis induces detrusor muscle relaxation via similar pathways.

\section{Production of NO and ATP}

It is recognised that NO is an essential element in the normal physiology of smooth muscle relaxation. There is an increasing number of studies to address the role of $\mathrm{NO}$ in preserving the normal function of a bladder and suggest it as a therapeutic target for bladder dysfunction. Inducible form of nitric oxide synthase (iNOS) knockout mice showed that the production of NO is vital to prevent detrusor dysfunction by promoting vasodilation and reducing platelet aggregation (Lemack, Zimmern, Vazquez, McConnell, \& Lin, 2000). Furthermore, reduced nitric oxide synthase (NOS) and increased NO production were reported to enhance urinary tract symptoms in patients with benign prostatic hyperplasia and bladder outlet obstruction (McVary, 2006). Administration of phosphodiesterase type 5 (PDE5) inhibitors such as tadalafil with NO-mediated relaxant effects have found to significantly reduce the lower urinary tract symptoms in men (Giuliano et al., 2013). Chiou et al. (2000) have demonstrated the NO-releasing effect 
of $O$. sinensis in their study, suggesting a possible mechanism of $O$. sinensis in promoting smooth muscle relaxation. Incubation of endothelium-intact rat thoracic aorta with $O$. sinensis mycelium protein extract produced a concentration-dependent relaxation response that can be inhibited by L-N ${ }^{\mathrm{G}}$-Nitro arginine methyl ester (L-NAME), a NOS inhibitor (Chiou et al., 2000). In the same study, intravenous administration of $32 \mathrm{mg} / \mathrm{kg}$ of the mycelium protein extract for 45 minutes was shown to reduce the mean arterial pressure (MAP) from $107 \pm 6$ to $49 \pm 3 \mathrm{mmHg}$, further suggesting its smooth muscle relaxation effect.

The role of ATP in the urinary bladder has been studied extensively as a therapeutic option for bladder dysfunction. ATP-induced relaxation in the urinary bladder has been documented and found to be associated with the activation of purinergic $\mathrm{P}_{2 Y}$ receptors (Boland, Himpens, Paques, Casteels, \& Gillis, 1993). Recently, with the use of vesicular nucleotide transporter (VNUT)-deficient mice, ATP has shown to play a crucial role in urine storage by maintaining bladder relaxation during the early cycle of filling (Nakagomi et al., 2016). This suggests the importance of ATP in regulating bladder smooth muscle tone via VNUT-mediated pathway. As a popular tonic and health booster, $O$. sinensis is often linked to the production of ATP (energy) in the body. Administration of methanolic extract of wild and cultured $O$. sinensis at a daily dose of $1 \mathrm{~g} / \mathrm{kg}$ for three days in mice has shown to enhance the myocardial mitochondrial ATP generation (Siu et al., 2004). Therefore, it is postulated that the production of ATP triggered by O. sinensis may also activate the purinergic $\mathrm{P}_{2 Y}$ receptors in the bladder smooth muscle. However, further investigation is needed as ATP also binds to $\mathrm{P}_{2 \mathrm{X}}$ receptors in the bladder to cause muscle contraction.

\section{Inhibiting the involuntary micturition}

Neurogenic $\mathrm{OAB}$ is often a secondary complication in patients with neurological disorders such as multiple sclerosis, Parkinson's disease, Alzheimer's disease and spinal cord injury due to impaired central inhibitory pathways or sensitisation of peripheral afferents (De Groat, 1997). In the search of new therapeutic targets in neurogenic OAB, the role of adenosine receptors in the control of detrusor neurotransmission and micturition reflex has been a major focus. It was discovered that reflex micturition can be inhibited by either activating the adenosine $A_{1}$ receptors or inhibiting the adenosine $\mathrm{A}_{2 \mathrm{~A}}$ receptors in the brain, spinal cord or bladder (Kitta et al., 2014). Kitta et al. (2014) also showed that intravesical perfusion of 2-chloro- $\mathrm{N}^{6}$-cyclopentyladenosine (CCPA), a selective adenosine $\mathrm{A}_{1}$ receptor agonist, was able to reduce bladder overactivity induced by dimethylsulfoxide in rats. Using human detrusor preparations in an isolated tissue bath system, the contractile responses to electrical field stimulation were inhibited by adenosine and selective adenosine $A_{1}$ receptor agonists in a concentration-dependent manner (Searl et al., 2016). In addition, $\mathrm{N}^{6}$-cyclopentyladenosine (CPA) and adenosine also reduced the amplitudes of the $\mathrm{P}_{2 \mathrm{x}}$ purinoceptormediated excitatory junctional potentials (EJP) without affecting the spontaneous EJP potentials. This suggests that the activation of prejunctional $A_{1}$ adenosine receptors may dampen detrusor neurotransmission (Searl et al., 2016). Moreover, the activation of adenosine $A_{1}$ receptor is imperative to the use of $\beta_{3}$-adrenoceptor agonist in increasing bladder storage capacity and prolonging intermicturition duration (Silva et al., 2017).

Purinergic active components such as adenosine and cordycepin (3'-deoxyadenosine) are major nucleosides in $O$. sinensis and they are often used as biomarkers to determine the authenticity and quality of the medicinal fungus (Hsu et al., 2002; Khan et al., 2015). In addition, cordycepin's high binding affinity at the adenosine $\mathrm{A}_{1}$ receptor has been documented, thus enable it to induce detrusor muscle relaxation (Hu et al., 2013). It is hypothesised that other nucleosides in O. sinensis may also exert similar effects due to their structural similarities with cordycepin.
Although bladder inflammation precludes the clinical diagnosis of $\mathrm{OAB}$, recent studies have drawn a link between the two due to elevation of inflammation-related biomarkers such as prostaglandin $\mathrm{E}_{2}\left(\mathrm{PGE}_{2}\right)$ and pro-inflammatory cytokines within the bladder, and urine in patients with $\mathrm{OAB}$ and other bladder conditions (Ghoniem et al., 2011; Hegele et al., 2014). Production of $\mathrm{PGE}_{2}$ in the bladder can be initiated by a stretch of the detrusor muscle, bladder nerve stimulation, damage of the bladder mucosa as well as inflammation mediators (Rahnama'i, van Koevringe, \& Van Kerrebroeck, 2013). Bladder infusion with $\mathrm{PGE}_{2}$ also shown to enhance micturition reflex in patients with OAB (Hegele et al., 2014). These findings have led to the suggestion of using $\mathrm{PGE}_{2}$ as a diagnostic biomarker for OAB (Y. J. Zhang \& Bai, 2014). O. sinensis and its bioactive components thus represent promising therapeutic options due to their well-documented anti-inflammatory property. Cordycepin, in particular, has displayed pronounced anti-inflammatory effect. Pre-treatment with cordycepin at 10,50 or $100 \mu \mathrm{M}$ for two hours has shown to diminish the production of $\mathrm{PGE}_{2}$ in human osteoarthritis chondrocytes pre-stimulated with IL-1 $\beta$ (Ying et al., 2014). A similar procedure was carried out using lipopolysaccharide (LPS)-induced nucleus pulposus (NP) cells and showed that cordycepin at $100 \mu \mathrm{M}$ significantly inhibited $\mathrm{PGE}_{2}$ production (Yan Li et al., 2016). It has to be noted that these concentrations studied were very high and unlikely to be achieved in vivo. Other than inhibiting the production of $\mathrm{PGE}_{2}$, cordycepin has shown to down-regulate the expression of TNF- $\alpha$, IL-6, IL-17A on LPS-stimulated murine spleen cells (Seo et al., 2013). Other bioactive components of $O$. sinensis with anti-inflammatory effects include cordymin and nucleosides. Cordymin has displayed inhibitory activities against TNF- $\alpha$ and IL-1 $\beta$, leading to suppression of inflammation (Qian et al., 2012). Nucleosides include adenine, adenosine, 2 '-deoxyadenosine and thymidine isolated from $O$. sinensis have inhibited the expression of inflammatory cytokines including TNF$\alpha$, IL-6 and IL-1ß in the cigarette smoke-stimulated RAW 264.7 macrophages (Sun et al., 2018).

\section{Anti-oxidative effect}

Among the elderly population and those with vascular disorders, bladder ischaemia may be an important factor in exaggerating the $\mathrm{OAB}$ symptoms. Accumulation of oxidative stress molecules in chronic ischaemic bladder is known to form a vicious cycle by causing further destruction on the bladder microcirculation, nerve fibres and smooth muscle cells through lipid peroxidation, protein oxidation and DNA damage (Nomiya et al., 2015). In addition, oxidative stress may amplify the muscarinic receptor activities, stimulate neurodegeneration and cause ultrastructural damage in the bladder (Azadzoi, Radisavljevic, Golabek, Yalla, \& Siroky, 2010). These lead to enhanced contraction of the bladder, reduced storage capacity and as a consequence incontinence. Therefore, anti-oxidants are being considered as one of the therapeutic options for OAB (Alexandre et al., 2016; Miyata et al., 2019). O. sinensis has displayed anti-oxidative effects in several studies, together with its anti-ageing and cytotoxic properties. Hot water extract (HWE) of $O$. sinensis has shown to inhibit lipid peroxidation and prevent accumulation of cholesteryl ester in low-density lipoproteininduced macrophages (Y. Yamaguchi, Kagota, Nakamura, Shinozuka, \& Kunitomo, 2000). It has also shown to suppress over $90 \%$ of linoleic peroxidation, surpassing $\alpha$-tocopherol, an eminent natural antioxidant (Dong \& Yao, 2008). Polysaccharide fraction of O. sinensis, CSP-1 has been found to possess a strong protective effect in rat pheochromocytoma PC12 cells by suppressing hydrogen peroxideinduced cell injury and lipid peroxidation during the ischaemic state (Shao P. Li et al., 2003). Phenols, flavonoids, nucleosides and nucleobases isolated from $O$. sinensis have also shown to neutralise free radicals in hypoxia-induced cells (Singh et al., 2013).

\section{SAFETY PROFILE}

To date, only a limited number of studies regarding its safety is available although this fungus has been used for centuries to treat many 
conditions. The presence of toxic metals such as cadmium, lead and arsenic in $O$. sinensis sourced from local herbal stores across five different regions of China suggests a widespread contamination in wild $O$. sinensis (Wei et al., 2017). This, on top of its restricted geographical distribution and added effects of large-scale harvests for financial purposes, had led to the novel approaches of cultivation of the pure mycelium or fruiting bodies of $O$. sinensis in recent years using different techniques such as solid-state fermentation and submerged fermentation. Its success thus provide safer and more affordable options for consumers as well as researchers to substantiate its uses (X. Li et al., 2019). Sub-acute toxicity of cultivated $O$. sinensis has been assessed using rodent models by different groups. Overall, $O$. sinensis did not induce toxicity and behaviour change in the animals throughout the treatment period (Fung, Lee, Tan, \& Pailoor, 2017; Meena, Singh, Negi, \& Ahmed, 2013). Furthermore, the treatment of $O$. sinensis at $1.2 \mathrm{~g}$ three times per day has improved the quality of life of patients without producing any apparent adverse reaction (N. Wang, Li, Huang, Chen, \& Chen, 2016).

\section{CONCLUSION}

The multifactorial etiology of $\mathrm{OAB}$ is a main challenge for clinicians to offer a holistic care and treatment to affected individuals . This mini review has highlighted that $O$. sinensis contains a wide range of bioactive components that may potentially alleviate $\mathrm{OAB}$ via different pathways. However, the exact bioactive components are currently not known as the discussed effects may be due to a particular chemical group or are the synergistic effects of several components. There are four possible mechanisms for $O$. sinensis to alleviate OAB. These include (1) promoting bladder smooth muscle relaxation, (2) preventing reflex micturition hence prolonging the filling stage, (3) suppressing inflammation, and (4) activating the anti-oxidative mechanism. The anti-inflammatory and anti-oxidative effects are thought to be particularly useful in patients with co-morbidities such as cardiovascular diseases and diabetes. Current studies suggest that artificially cultivated $O$. sinensis possesses similar bioactivities with the wild type and is a safer and cheaper alternative for consumers. Given that $O$. sinensis is used traditionally for frequent urination and nocturia, more research should be performed in this respect to substantiate its therapeutic benefits.

\section{DISCLOSURES}

The authors declare no conflicts of interest in this work.

\section{ACKNOWLEDGMENTS}

This work was supported by LiGNO Biotech Sdn Bhd (LiGNO). Pang Li Yin is a recipient of the Scholarship for PhD in Faculty of Science and Engineering awarded by University of Nottingham Malaysia.

\section{REFERENCES}

Abrams, P., Kelleher, C. J., Kerr, L. A., \& Rogers, R. G. (2000). Overactive bladder significantly affects quality of life. American Journal of Managed Care, 6(11 SUPPL.). Retrieved from https://pubmed.ncbi.nlm.nih.gov/11183901/

Alexandre, E. C., Calmasini, F. B., de Oliveira, M. G., Silva, F. H., da Silva, C. P. V., André, D. M., ... Antunes, E. (2016). Chronic treatment with resveratrol improves overactive bladder in obese mice via antioxidant activity. European Journal of Pharmacology, 788, 29-36.

https://doi.org/10.1016/j.ejphar.2016.06.017

Apodaca, G., Kiss, S., Ruiz, W., Meyers, S., Zeidel, M., \& Birder, L. (2003). Disruption of bladder epithelium barrier function after spinal cord injury. American Journal of Physiology - Renal Physiology, 284(5 53-5).

https://doi.org/10.1152/ajprenal.00359.2002

Athanasopoulos, A., \& Giannitsas, K. (2011). An overview of the clinical use of antimuscarinics in the treatment of overactive bladder. Advances in Urology. https://doi.org/10.1155/2011/820816

Azadzoi, K. M., Radisavljevic, Z. M., Golabek, T., Yalla, S. V., \& Siroky, M. B. (2010). Oxidative Modification of Mitochondrial Integrity and Nerve Fiber Density in the Ischemic Overactive Bladder. Journal of Urology, 183(1), 362369. https://doi.org/10.1016/j.juro.2009.08.103

Bao, Z. D., Wu, Z. G., \& Zheng, F. (1994). Amelioration of aminoglycoside nephrotoxicity by Cordyceps sinensis in old patients. Zhongguo Zhong Xi Yi Jie He Za Zhi Zhongguo Zhongxiyi Jiehe Zazhi = Chinese Journal of Integrated Traditional and Western Medicine / Zhongguo Zhong Xi Yi Jie He Xue Hui, Zhongguo Zhong Yi Yan Jiu Yuan Zhu Ban, 14(5).

Boland, B., Himpens, B., Paques, C., Casteels, R., \& Gillis, J. M. (1993). ATP induced-relaxation in the mouse bladder smooth muscle. British Journal of Pharmacology, 108(3), 749-753.

https://doi.org/10.1111/j.1476-5381.1993.tb12872.x

Brading, A. F. (1997). A myogenic basis for the overactive bladder. Urology, 50(6 SUPPL. A), 57-67. https://doi.org/10.1016/S0090-4295(97)00591-8

Chatterjee, R., Srinivasan, K. S., \& Maiti, P. C. (1957). Cordyceps sinensis (Berkeley) Saccardo: Structure of Cordycepic Acid. Journal of the American Pharmaceutical Association (Scientific Ed.), 46(2), 114-118. https://doi.org/10.1002/jps.3030460211

Chen, H., Li, S., Wang, P., Yan, S., Hu, L., Pan, X., .. Leung, G. P. (2014). Endothelium-dependent and-independent relaxation of rat aorta induced by extract of Schizophyllum commune. Phytomedicine, 21(11), 1230-1236. https://doi.org/10.1016/j.phymed.2014.06.008

Chiou, W. F., Chang, P. C., Chou, C. J., \& Chen, C. F. (2000). Protein constituent contributes to the hypotensive and vasorelaxant activities of Cordyceps sinensis. Life Sciences, 66(14), 1369-1376. https://doi.org/10.1016/S0024-3205(00)00445-8

Chughtai, B., Kavaler, E., Lee, R., Te, A., Kaplan, S. A., \& Lowe, F. (2013). Use of herbal supplements for overactive bladder. Reviews in Urology, 15(3), 93-96. Retrieved from

http://www.ncbi.nlm.nih.gov/pubmed/24223020\%0Ahttp://www.pubmedce ntral.nih.gov/articlerender.fcgi?artid=PMC3821987

Chung, H. C., Lee, C. K., Park, K. H., \& Jeong, S. W. (2015). Bladder outlet obstruction causes up-regulation of nicotinic acetylcholine receptors in bladder-projecting pelvic ganglion neurons. Brain Research, 1602(C), 111118. https://doi.org/10.1016/j.brainres.2015.01.026

Coyne, K. S., Zhou, Z., Bhattacharyya, S. K., Thompson, C. L., Dhawan, R., \& Versi, E. (2003). The prevalence of nocturia and its effect on health-related quality of life and sleep in a community sample in the USA. BJU International, Vol. 92, pp. 948-954.

https://doi.org/10.1111/j.1464-410X.2003.04527.x

De Groat, W. C. (1997). Neurologic basis for the overactive bladder. Urology, 50(6 SUPPL. A), 36-52. https://doi.org/10.1016/S0090-4295(97)00587-6

de Groat, W. C., \& Yoshimura, N. (2012). Plasticity in reflex pathways to the lower urinary tract following spinal cord injury. Experimental Neurology, Vol. 235 pp. 123-132. https://doi.org/10.1016/i.expneurol.2011.05.003

Dong, C. H., \& Yao, Y. J. (2008). In vitro evaluation of antioxidant activities of aqueous extracts from natural and cultured mycelia of Cordyceps sinensis. LWT - Food Science and Technology, 41(4), 669-677. https://doi.org/10.1016/i.lwt.2007.05.002

Endeshaw, Y. W., Schwartz, A. V., Stone, K., Caserotti, P., Harris, T., Smagula, S., \& Satterfield, S. (2016). Nocturia, insomnia symptoms and mortality among older men: The health, aging and body composition study. Journal of Clinical Sleep Medicine, 12(6), 789-796. https://doi.org/10.5664/jicsm.5870

Fung, S. Y., Cheong, P. C. H., Tan, N. H., Ng, S. T., \& Tan, C. S. (2018). Nutrient and chemical analysis of fruiting bodies of a cultivar of the Chinese caterpillar mushroom, Ophiocordyceps sinensis (Ascomycetes). International Journal of Medicinal Mushrooms, 20(5), 459-469. H https://doi.org/10.1615/IntJMedMushrooms.2018026252

Fung, S. Y., Lee, S. S., Tan, N. H., \& Pailoor, J. (2017). Safety assessment of cultivated fruiting body of Ophiocordyceps sinensis evaluated through subacute toxicity in rats. Journal of Ethnopharmacology, 206, 236-244. https://doi.org/10.1016/j.jep.2017.05.037

Ghoniem, G., Faruqui, N., Elmissiry, M., Mahdy, A., Abdelwahab, H., Oommen, M., \& Abdel-Mageed, A. B. (2011). Differential profile analysis of urinary cytokines in patients with overactive bladder. International Urogynecology Journal, 22(8), 953-961. https://doi.org/10.1007/s00192-011-1401-8

Giuliano, F., Ückert, S., Maggi, M., Birder, L., Kissel, J., \& Viktrup, L. (2013). The mechanism of action of phosphodiesterase type 5 inhibitors in the treatment of lower urinary tract symptoms related to benign prostatic hyperplasia. European Urology, Vol. 63, pp. 506-516. https://doi.org/10.1016/j.eururo.2012.09.006

Hanna-Mitchell, A. T., Kashyap, M., Chan, W. V., Andersson, K. E., \& Tannenbaum, C. (2014). Pathophysiology of idiopathic overactive bladder and the success of treatment: A systematic review from ICI-RS 2013. 
Neurourology and Urodynamics, Vol. 33, pp. 611-617. https://doi.org/10.1002/nau.22582

He, Q., Wang, Z., Liu, G., Daneshgari, F., MacLennan, G. T., \& Gupta, S. (2016). Metabolic syndrome, inflammation and lower urinary tract symptoms: Possible translational links. Prostate Cancer and Prostatic Diseases, 19(1), 713. https://doi.org/10.1038/pcan.2015.43

Hegele, A., Knippschild, S., Frohme, C., Hänze, J., Olbert, P., \& Hofmann, R. (2014). Changes in prostaglandin E2 in patients with idiopathic overactive bladder syndrome after botulinum toxin type A treatment: Is there a clinical benefit? BMC Urology, 14(1). https://doi.org/10.1186/1471-2490-14-85

Hsu, T. H., Shiao, L. H., Hsieh, C., \& Chang, D. M. (2002). A comparison of the chemical composition and bioactive ingredients of the Chinese medicinal mushroom DongChongXiaCao, its counterfeit and mimic, and fermented mycelium of Cordyceps sinensis. Food Chemistry, 78(4), 463-469. https://doi.org/10.1016/S0308-8146(02)00158-9

Hu, Z., Lee, C. Il, Shah, V. K., Oh, E. H., Han, J. Y., Bae, J. R., ... Oh, K. W. (2013). Cordycepin increases nonrapid eye movement sleep via adenosine receptors in rats. Evidence-Based Complementary and Alternative Medicine, 2013. https://doi.org/10.1155/2013/840134

Ji, N. F., Yao, L. S., Li, Y., He, W., Yi, K. S., \& Huang, M. (2011). Polysaccharide of Cordyceps sinensis enhances cisplatin cytotoxicity in non-small cell lung cancer H157 cell line. Integrative Cancer Therapies, 10(4), 359-367. https://doi.org/10.1177/1534735410392573

Jia, J. M., Ma, X. C., Wu, C. F., Wu, L. J., \& Hu, G. S. (2005). Cordycedipeptide A, a new cyclodipeptide from the culture liquid of Cordyceps sinensis (BERK.) SACC. Chemical and Pharmaceutical Bulletin, 53(5), 582-583. https://doi.org/10.1248/cpb.53.582

Khan, M. S., Parveen, R., Mishra, K., Tulsawani, R., \& Ahmad, S. (2015). Determination of nucleosides in Cordyceps sinensis and Ganoderma lucidum by high performance liquid chromatography method. Journal of Pharmacy and Bioallied Sciences, 7(4), 264-266. https://doi.org/10.4103/0975-7406.168022

Kitta, T., Chancellor, M. B., De Groat, W. C., Kuno, S., Nonomura, K., \& Yoshimura, N. (2014). Roles of adenosine A1 and A2A receptors in the control of micturition in rats. Neurourology and Urodynamics, 33(8), 12591265 https://doi.org/10.1002/nau.22487

Lee, M. K., Li, X., Yap, A. C. S., Cheung, P. C. K., Tan, C. S., Ng, S. T., ... Fung, S. Y. (2018). Airway relaxation effects of water-soluble sclerotial extract from Lignosus rhinocerotis. Frontiers in Pharmacology, 9(MAY), 461. https://doi.org/10.3389/fphar.2018.00461

Leiria, L. O. S., Mõnica, F. Z. T., Carvalho, F. D. G. F., Claudino, M. A., FrancoPenteado, C. F., Schenka, A., ... Antunes, E. (2011). Functional, morphological and molecular characterization of bladder dysfunction in streptozotocin-induced diabetic mice: Evidence of a role for L-type voltageoperated Ca 2+ channels. British Journal of Pharmacology, 163(6), 12761288.

\section{https://doi.org/10.1111/j.1476-5381.2011.01311.x}

Lemack, G. E., Zimmern, P. E., Vazquez, D., McConnell, J. D., \& Lin, V. K. (2000). Altered response to partial bladder outlet obstruction in mice lacking inducible nitric oxide synthase. Journal of Urology, 163(6), 1981-1987. https://doi.org/10.1016/S0022-5347(05)67614-8

Li, S. P., Li, P., Dong, T. T. X., \& Tsim, K. W. K. (2001). Anti-oxidation activity of different types of natural Cordyceps sinensis and cultured Cordyceps mycelia. Phytomedicine. https://doi.org/10.1078/0944-7113-00030

Li, S. P., Zhang, G. H., Zeng, Q., Huang, Z. G., Wang, Y. T., Dong, T. T. X., \& Tsim, K. W. K. (2006). Hypoglycemic activity of polysaccharide, with antioxidation, isolated from cultured Cordyceps mycelia. Phytomedicine. https://doi.org/10.1016/j.phymed.2005.02.002

Li, Shao P., Zhao, K. J., Ji, Z. N., Song, Z. H., Dong, T. T. X., Lo, C. K., .. Tsim, K. W. K. (2003). A polysaccharide isolated from Cordyceps sinensis, a traditional Chinese medicine, protects $\mathrm{PC} 12$ cells against hydrogen peroxideinduced injury. Life Sciences, 73(19), 2503-2513. https://doi.org/10.1016/S0024-3205(03)00652-0

Li, X., Liu, Q., Li, W., Li, Q., Qian, Z., Liu, X., \& Dong, C. (2019). A breakthrough in the artificial cultivation of Chinese cordyceps on a large-scale and its impact on science, the economy, and industry. Critical Reviews in Biotechnology, 39(2), 181-191. https://doi.org/10.1080/07388551.2018.1531820

Li, Yan, Li, K., Mao, L., Han, X., Zhang, K., Zhao, C., \& Zhao, J. (2016). Cordycepin inhibits LPS-induced inflammatory and matrix degradation in the intervertebral disc. PeerJ Life and Environment, 2016(5) https://doi.org/10.7717/peeri.1992

Li, Yi, Wang, X. L., Jiao, L., Jiang, Y., Li, H., Jiang, S. P., ... Yao, Y. J. (2011). A survey of the geographic distribution of Ophiocordyceps sinensis. Journal of
Microbiology, 49(6), 913-919

https://doi.org/10.1007/s12275-011-1193-z

Liu, H. P., Chen, G. L., Liu, P., \& Xu, X. P. (2009). Amlodipine alone or combined with terazosin improves lower urinary tract disorder in rat models of benign prostatic hyperplasia or detrusor instability: Focus on detrusor overactivity. BJU International, 104(11), 1752-1757. https://doi.org/10.1111/j.1464-410X.2009.08659 X

Liu, Y., Wang, J., Wang, W., Zhang, H., Zhang, X., \& Han, C. (2015). The chemical constituents and pharmacological actions of Cordyceps sinensis. EvidenceBased Complementary and Alternative Medicine, 2015, 12 https://doi.org/10.1155/2015/575063

Lo, H. C., Hsieh, C., Lin, F. Y., \& Hsu, T. H. (2013). A systematic review of the mysterious caterpillar fungus Ophiocordyceps sinensis in DongChongXiaCao (Dōng Chóng Xià Căo) and related bioactive ingredients. Journal of Traditional and Complementary Medicine, Vol. 3, pp. 16-32. https://doi.org/10.1016/\$2225-4110(16)30164-X

Lu, W. J., Chang, N. C., Jayakumar, T., Liao, J. C., Lin, M. J., Wang, S. H., ... Sheu, J. R. (2014). Ex vivo and in vivo studies of CME-1, a novel polysaccharide purified from the mycelia of Cordyceps sinensis that inhibits human platelet activation by activating adenylate cyclase/cyclic AMP. Thrombosis Research, 134(6), 1301-1310. https://doi.org/10.1016/j.thromres.2014.09.023

Mamta, Mehrotra, S., Amitabh, Kirar, V., Vats, P., Nandi, S. P., .. Misra, K. (2015) Phytochemical and antimicrobial activities of Himalayan Cordyceps sinensis (Berk.) Sacc. Indian Journal of Experimental Biology, 53(1), 36-43.

Mattiasson, A., Ekstrom, B., \& Andersson, K. E. (1989). Effects of intravesical instillation of verapamil in patients with detrusor hyperactivity. Journal of Urology. https://doi.org/10.1016/S0022-5347(17)40635-5

McVary, K. (2006). Lower urinary tract symptoms and sexual dysfunction Epidemiology and pathophysiology. BJU International, 97(SUPPL. 2), 23-28. https://doi.org/10.1111/j.1464-410X.2006.06102.X

Meena, H., Singh, K. P., Negi, P. S., \& Ahmed, Z. (2013). Sub-acute toxicity of cultured mycelia of Himalayan entomogenous fungus Cordyceps sinensis (Berk.) Sacc. in rats. Indian Journal of Experimental Biology, 51(5), 381-387.

Miyata, Y., Matsuo, T., Mitsunari, K., Asai, A., Ohba, K., \& Sakai, H. (2019). A review of oxidative stress and urinary dysfunction caused by bladder outlet obstruction and treatments using antioxidants. Antioxidants, 8(5). https://doi.org/10.3390/antiox8050132

Nakagomi, H., Yoshiyama, M., Mochizuki, T., Miyamoto, T., Komatsu, R., Imura, Y., ... Koizumi, S. (2016). Urothelial ATP exocytosis: Regulation of bladder compliance in the urine storage phase. Scientific Reports, Vol. 6 https://doi.org/10.1038/srep29761

National Institute For Health and Care, \& Excellence. (2015). Urinary incontinence | Guidance and guidelines | NICE. National Institute of Health and Clinical Evidence. Retrieved from https://www.nice.org.uk/guidance/cg171

Nomiya, M., Andersson, K. E., \& Yamaguchi, O. (2015). Chronic bladder ischemia and oxidative stress: New pharmacotherapeutic targets for lower urinary tract symptoms. International Journal of Urology. https://doi.org/10.1111/iju.12652

Park, J. S., Jung, H. Do, Cho, Y. S., Jin, M. H., \& Hong, C. H. (2018). Neonatal bladder irritation is associated with vanilloid receptor TRPV1 expression in adult rats. International Neurourology Journal, 22(3), 169-176. https://doi.org/10.5213/inj.1836020.101

Peng, Y., Tao, Y., Wang, Q., Shen, L., Yang, T., Liu, Z., \& Liu, C. (2014). Ergosterol is the active compound of cultured mycelium cordyceps sinensis on antiliver fibrosis. Evidence-Based Complementary and Alternative Medicine, 2014 https://doi.org/10.1155/2014/537234

Qi, W., Zhang, Y., Yan, Y. B., Lei, W., Wu, Z. X., Liu, N., ... Fan, Y. (2013). The protective effect of cordymin, a peptide purified from the medicinal mushroom Cordyceps sinensis, on diabetic osteopenia in alloxan-induced diabetic rats. Evidence-Based Complementary and Alternative Medicine, 2013. https://doi.org/10.1155/2013/985636

Qian, G. M., Pan, G. F., \& Guo, J. Y. (2012). Anti-inflammatory and antinociceptive effects of cordymin, a peptide purified from the medicinal mushroom Cordyceps sinensis. Natural Product Research, 26(24), 2358-2362. https://doi.org/10.1080/14786419.2012.658800

Rahnama'i, M. S., van Koevringe, G. A., \& Van Kerrebroeck, P. E. (2013). Overactive bladder syndrome and the potential role of prostaglandins and phosphodiesterases: An introduction. Nephro-Urology Monthly, 5(4), 933944. https://doi.org/10.5812/numonthly.14087

Searl, T. J., Dynda, D. I., Alanee, S. R., El-Zawahry, A. M., McVary, K. T., \& Silinsky, E. M. (2016). Al Adenosine Receptor-Mediated Inhibition of Parasympathetic Neuromuscular Transmission in Human and Murine Urinary Bladder. The Journal of Pharmacology and Experimental 
Therapeutics, 356(1), 116-122.

https://doi.org/10.1124/ipet.115.228882

Seo, M. J., Kim, M. J., Lee, H. H., Park, J. U., Kang, B. W., Kim, G. Y., ... Jeong, Y. K. (2013). Effect of cordycepin on the expression of the inflammatory cytokines TNF-alpha, IL-6, and IL-17a in C57bL/6 mice. Journal of Microbiology and Biotechnology, 23(2), 156-160. https://doi.org/10.4014/jmb.1211.11032

Silva, I., Costa, A. F., Moreira, S., Ferreirinha, F., Magalhães-Cardoso, M. T., Calejo, I., .. Correia-de-Sá, P. (2017). Inhibition of cholinergic neurotransmission by $\beta 3$-adrenoceptors depends on adenosine release and A1-receptor activation in human and rat urinary bladders. American Journal of Physiology - Renal Physiology, 313(2), F388-F403. https://doi.org/10.1152/aiprenal.00392.2016

Singh, M., Tulsawani, R., Koganti, P., Chauhan, A., Manickam, M., \& Misra, K. (2013). Cordyceps sinensis increases hypoxia tolerance by inducing heme oxygenase-1 and metallothionein via Nrf2 activation in human lung epithelial cells. BioMed Research International, 2013, 1-13. https://doi.org/10.1155/2013/569206

Siu, K. M., Mak, D. H. F., Chiu, P. Y., Poon, M. K. T., Du, Y., \& Ko, K. M. (2004). Pharmacological basis of "Yin-nourishing" and "Yang-invigorating" actions of Cordyceps, a Chinese tonifying herb. Life Sciences, 76(4), 385-395. https://doi.org/10.1016/j.lfs.2004.07.014

Srikrishna, S., Robinson, D., Cardozo, L., \& Vella, M. (2007). Management of overactive bladder syndrome. Postgraduate Medical Journal, 83(981), 481486.

https://doi.org/10.1136/pgmj.2007.057232

Steers, W. D. (2002). Pathophysiology of overactive bladder and urge urinary incontinence. Reviews in Urology, 4 Suppl 4, S7-S18. Retrieved from http://www.ncbi.nlm.nih.gov/pubmed/16986023\%0Ahttp://www.pubmedce ntral.nih.gov/articlerender.fcgi?artid=PMC1476015

Sui, G., Fry, C. H., Malone-Lee, J., \& Wu, C. (2009). Aberrant Ca2+ oscillations in smooth muscle cells from overactive human bladders. Cell Calcium, 45(5), 456-464.

https://doi.org/10.1016/j.ceca.2009.03.001

Sun, X., Dong, Z., Li, N., Feng, X., Liu, Y., Li, A., ... Zhao, Z. (2018). Nucleosides isolated from ophiocordyceps sinensis inhibit cigarette smoke extractinduced inflammation via the SIRT1-nuclear factor-kB/p65 pathway in RAW264.7 macrophages and in COPD mice. International Journal of COPD, 13, 2821-2832.

https://doi.org/10.2147/COPD.S172579

Tyagi, P. (2011). Pathophysiology of the urothelium and detrusor. Canadian Urological Association Journal, 5(5), S128-\$130. https://doi.org/10.5489/cuaj.11181

Tyagi, P., Barclay, D., Zamora, R., Yoshimura, N., Peters, K., Vodovotz, Y., \& Chancellor, M. (2010). Urine cytokines suggest an inflammatory response in the overactive bladder: A pilot study. International Urology and Nephrology, 42(3), 629-635. https://doi.org/10.1007/s11255-009-9647-5

Wang, N., Li, J., Huang, X., Chen, W., \& Chen, Y. (2016). Herbal Medicine Cordyceps sinensis Improves Health-Related Quality of Life in Moderate-toSevere Asthma. Evidence-Based Complementary and Alternative Medicine, 2016(6134593). https://doi.org/10.1155/2016/6134593

Wang, Z., Cheng, Z., Cristofaro, V., Li, J., Xiao, X., Gomez, P., ... Olumi, A. F. (2012). Inhibition of TNF- $\alpha$ improves the bladder dysfunction that is associated with type 2 diabetes. Diabetes, 61(8), 2134-2145. https://doi.org/10.2337/db11-1763

Wang, Z. M., Peng, X., Lee, K. L. D., Tang, J. C. O., Cheung, P. C. K., \& Wu, J. Y. (2011). Structural characterisation and immunomodulatory property of an acidic polysaccharide from mycelial culture of Cordyceps sinensis fungus CsHK1. Food Chemistry, 125(2), 637-643. https://doi.org/10.1016/j.foodchem.2010.09.052

Wei, X., Hu, H., Zheng, B., Arslan, Z., Huang, H. C., Mao, W., \& Liu, Y. M. (2017). Profiling metals in Cordyceps sinensis by using inductively coupled plasma mass spectrometry. Analytical Methods, 9(4), 724-728. https://doi.org/10.1039/C6AY02524B

Winder, M., Tobin, G., Zupančičc, D., \& Romih, R. (2014). Signalling molecules in the urothelium. BioMed Research International, 2014. https://doi.org/10.1155/2014/297295

Winkler, D. (2011). Caterpillar Fungus (Ophiocordyceps sinensis) Production and Sustainability on the Tibetan Plateau and in the Himalayas. Asian Medicine, 5(2), 291-316 https://doi.org/10.1163/157342109X568829

Winston, D., \& Maimes, S. (2007). Adaptogens: Herbs for Strength, Stamina, and Stress Relief. In Healing Arts Press (1st ed.). Retrieved from $\underline{\text { htpp://www.holy- }}$ basil.com/6865.html

World Health Organization. (2017). Integrated Care for Older People: guidelines on community-level interentions to manage declines in intrinsic capacity
Retrieved from https://www.who.int/ageing/publications/guidelinesicope/en/

Yalin, W., Ishurd, O., Cuirong, S., \& Yuanjiang, P. (2005). Structure analysis and antitumor activity of (1 $1 \rightarrow 3)-\beta$-D-glucans (cordyglucans) from the mycelia of Cordyceps sinensis. Planta Medica, 71(4), 381-384. https://doi.org/10.1055/s-2005-864111

Yamaguchi, O., Kakizaki, H., Homma, Y., Igawa, Y., Takeda, M., Nishizawa, O., ... Kuroishi, K. (2015). Safety and efficacy of mirabegron as "add-on" therapy in patients with overactive bladder treated with solifenacin: A post-marketing open-label study in Japan (MILAI study). BJU International, 116(4), 612-622. https://doi.org/10.1111/bju.13068

Yamaguchi, Y., Kagota, S., Nakamura, K., Shinozuka, K., \& Kunitomo, M. (2000). Antioxidant activity of the extracts from fruiting bodies of cultured Cordyceps sinensis. Phytotherapy Research, 14(8), 647-649. https://doi.org/10.1002/1099-1573(200012)14:8<647::AIDPTR670>3.0.CO:2-W

Yang, F. Q., Li, D. Q., Feng, K., Hu, D. J., \& Li, S. P. (2010). Determination of nucleotides, nucleosides and their transformation products in Cordyceps by ion-pairing reversed-phase liquid chromatography-mass spectrometry. Journal of Chromatography A, 1217(34), 5501-5510 https://doi.org/10.1016/i.chroma.2010.06.062

Yang, L. Y., Chen, A., Kuo, Y. C., \& Lin, C. Y. (1999). Efficacy of a pure compound H1-A extracted from Cordyceps sinensis on autoimmune disease of MRL lpr/lpr mice. Journal of Laboratory and Clinical Medicine, 134(5), 492-500. https://doi.org/10.1016/S0022-2143(99)90171-3

Yang, M. L., Kuo, P. C., Hwang, T. L., \& Wu, T. S. (2011). Anti-inflammatory principles from Cordyceps sinensis. Journal of Natural Products. https://doi.org/10.1021/np100902f

Ye, M. Q., Hu, Z., Fan, Y., He, L., Xia, F. B., \& Zou, G. L. (2004). Purification and characterization of an acid deoxyribonuclease from the cultured mycelia of Cordyceps sinensis. Journal of Biochemistry and Molecular Biology, 37(4), $466-473$

https://doi.org/10.5483/BMBRep.2004.37.4.466

Ying, X., Peng, L., Chen, H., Shen, Y., Yu, K., \& Cheng, S. (2014). Cordycepin prevented IL- $\beta$-induced expression of inflammatory mediators in human osteoarthritis chondrocytes. International Orthopaedics, 38(7), 1519-1526. https://doi.org/10.1007/s00264-013-2219-4

Zhang, Y. J., \& Bai, Q. (2014). Urinary prostaglandins E2 correlates to overactive bladder symptoms in patients with benign prostatic hyperplasia. National Journal of Andrology, 20(3), 244-248. Retrieved from https://pubmed.ncbi.nlm.nih.gov/24738462/

Zhang, Z. J., Luo, H. L., \& Li, J. S. (1997). Clinical and experimental studies on elimination of oxygen free radical of jinshuibao capsule in treating senile deficiency syndrome and its deoxyribonucleic acid damage repairing effects. Chinese Journal of Integrated Traditional and Western Medicine, 17(1), 3538. Retrieved from https://pubmed.ncbi.nlm.nih.gov/9812650/

Citation:

Pang, L.-Y., Tan, C.-S., Ng, S.-T., Lim, K.-H., Then, S.-M., \& Kang Nee, T. (2020) Ophiocordyceps sinensis: a prominent source of bioactive components for alleviating overactive bladder. Life Sciences, Medicine and Biomedicine, 4(9). https://doi.org/10.28916/lsmb.4.9.2020.67

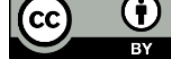

Copyright (C) 2020 by the Author(s). Life Sciences, Medicine and Biomedicine (ISSN: 2600-7207) Published by Biome Journals - Biome Scientia Sdn Bhd. Attribution 4.0 International (CC BY 4.0). This open access article is distributed based on the terms and conditions of the Creative Commons Attribution license https://creativecommons.org/licenses/by/4.0/

Life Sciences, Medicine and Biomedicine ISSN: 2600-7207 